\title{
Secondary prevention of coronary heart disease in older patients after the national service framework: population based study
}

Sheena E Ramsay, Peter H Whincup, Debbie A Lawlor, Olia Papacosta, Lucy T Lennon, Mary C Thomas, Shah Ebrahim, Richard W Morris

Department of

Primary Care and Population

Sciences, Royal Free and University College Medical School, London NW3 2PF

Sheena E Ramsay research fellow

Peter H Whincup

professor of

cardiovascular

epidemiology

Olia Papacosta

research statistician

Lucy T Lennon

research

administrator

Mary C Thomas

research assistant

Richard W Morris

reader in medical

statistics

Department of Social Medicine,

University of

Bristol, Bristol

BS8 2PR

Debbie A Lawlor

senior lecturer in

epidemiology and

public health medicine

Shah Ebrahim

professor in

epidemiology of

ageing

Correspondence to:

S E Ramsay

s.ramsay@

pcps.ucl.ac.uk

BMJ 2006;332:144-5

\begin{abstract}
Objective To examine the extent of uptake of medication for secondary prevention of coronary heart disease in older British men and women before (1998-2001) and after (2003) the implementation of the national service framework.

Design Two population based, longitudinal studies of men and women aged 60-79 in 1998-2001, based in one general practice in each of 24 British towns. Participants Men and women with established coronary heart disease at the two time points (respectively 817 and 465 in 1998-2001, 857 and 548 in 2003), aged 60-79 in 1998-2001.

Main outcome measures Prevalence of use of antiplatelet medication, statins, $\beta$ blockers, angiotensin converting enzyme (ACE) inhibitors, and other blood pressure lowering treatments (individually and in combination) assessed in 1998-2001 and 2003.

Results Between 1998-2001 and 2003, the use of all individual drugs had increased in both men and women, especially for statins (from 34\% to $65 \%$ in men and from $48 \%$ to $67 \%$ in women with myocardial infarction). However, less than half received $\beta$ blockers and ACE inhibitors, even by 2003. Prevalences of medication use were lower in patients with angina than in those with myocardial infarction. The proportions of patients receiving more than one drug increased over time; by 2003 about half of patients with myocardial infarction and a third of those with angina were receiving antiplatelet medication, statins, and blood pressure lowering treatments.

Conclusions Between 1998-2001 and 2003, statin uptake and the use of combined drug treatment in elderly men and women increased markedly. Further potential exists, however, for reducing the risk of recurrent coronary heart disease in older patients, particularly by improving the uptake of medication among angina patients, and by more extensive use of blood pressure lowering treatment (particularly with $\beta$ blockers and ACE inhibitors).
\end{abstract}

\section{Introduction}

Secondary prevention of coronary heart disease is an important component of the national service framework for coronary heart disease. ${ }^{1}$ Recently it has been increasingly recognised that using drugs in combination (particularly antiplatelet medication, statins, and blood pressure lowering drugs) could produce substantial relative reductions in the risk of coronary heart disease of up to $75 \%$ or more. ${ }^{2}$ Most published reports of secondary prevention in the United Kingdom are based on data predating the national service framework in 2000. We used two longitudinal studies to examine the extent of uptake of secondary prevention (including combination treatment) in older British men and women before and after the implementation of the national service framework.

\section{Methods}

The British regional heart study and the British women's heart and health study are population based studies of cardiovascular disease in British towns representing all major British regions. ${ }^{34}$ We reviewed general practice records every two years to obtain information on diagnoses of coronary heart disease. We used questionnaires in 1998-2000 (mid-year 1999; response rate $77 \%)$ and $2003(80 \%)$ in the men's study, and 1999-2001 (mid-year 2000; 60\%) and 2003 (90\%) in the women's study to collect data on medication use. We examined the prevalence of medication use among prevalent coronary heart disease cases at each time point; the populations differed slightly, supplemented by new coronary heart disease cases and attenuated by death and non-response.

\section{Results}

Between 1998-2001 and 2003, the prevalence of use of all individual drugs had increased in both men and women, especially for statins, which doubled in usage (table). Prevalences of medication use were very similar in men and women, with the exception of antiplatelet drugs, which were consistently lower in women. In 2003 , although about $80 \%$ of men and women with a history of myocardial infarction were taking antiplatelet medication, only two thirds were receiving statins, and less than half were receiving $\beta$ blockers and $\mathrm{ACE}$ inhibitors. Prevalences of medication use were generally lower in patients with angina than in patients with myocardial infarction.

By 2003, more than 90\% of subjects with myocardial infarction and more than $80 \%$ of those with angina were receiving at least one medication. The number of patients receiving more than one drug had increased, and by 2003 about half of patients with myocardial infarction and a third of those with angina were receiving three drug classes.

\section{Discussion}

Between 1998-2001 and 2003, statin uptake and the use of combinations of drugs in elderly men and women increased markedly; a key publication highlighting likely benefits of combination treatment appeared mid-way through $2003 .^{2}$ By 2003 , antiplatelet

This article was posted on bmj.com on 9 January 2006: http://bmj.com cgi/doi/10.1136/bmj.38704.770127.BE 
Prevalence of medication use for secondary prevention in patients with myocardial infarction or angina. Values are numbers (percentages) of patients unless otherwise indicated

\begin{tabular}{|c|c|c|c|c|c|c|c|c|}
\hline & \multicolumn{4}{|c|}{ Myocardial infarction } & \multicolumn{4}{|c|}{ Angina } \\
\hline & \multicolumn{2}{|c|}{ Men } & \multicolumn{2}{|c|}{ Women } & \multicolumn{2}{|c|}{ Men } & \multicolumn{2}{|c|}{ Women } \\
\hline & $\begin{array}{c}1998-2000 \\
(\mathrm{n}=332)\end{array}$ & $\begin{array}{c}2003 \\
(\mathrm{n}=336)\end{array}$ & $\begin{array}{c}1999-2001 \\
(n=91)\end{array}$ & $\begin{array}{c}2003 \\
(\mathrm{n}=109)\end{array}$ & $\begin{array}{c}1998-2000 \\
(\mathrm{n}=485)\end{array}$ & $\begin{array}{c}2003 \\
(n=521)\end{array}$ & $\begin{array}{c}1999-2001 \\
(\mathrm{n}=374)\end{array}$ & $\begin{array}{c}2003 \\
(\mathrm{n}=439)\end{array}$ \\
\hline No of subjects at both time points & \multicolumn{2}{|c|}{283} & \multicolumn{2}{|c|}{87} & \multicolumn{2}{|c|}{412} & \multicolumn{2}{|c|}{352} \\
\hline \multicolumn{9}{|l|}{ Individual treatment } \\
\hline Antiplatelet drugs & $272(82)$ & $297(88)$ & $64(70)$ & $85(78)$ & $318(66)$ & $395(76)$ & $162(43)$ & $255(58)$ \\
\hline Statins & $112(34)$ & $219(65)$ & $44(48)$ & $73(67)$ & $106(22)$ & $257(49)$ & $92(25)$ & $197(45)$ \\
\hline$\beta$ blockers & $118(36)$ & $147(44)$ & $33(36)$ & $46(42)$ & $143(30)$ & $190(37)$ & $116(31)$ & $167(38)$ \\
\hline $\begin{array}{l}\text { Angiotensin converting enzyme (ACE) } \\
\text { inhibitors }\end{array}$ & $92(28)$ & $147(44)$ & $26(29)$ & $35(32)$ & $81(17)$ & $155(30)$ & $75(20)$ & $135(31)$ \\
\hline $\begin{array}{l}\text { Blood pressure lowering drugs other } \\
\text { than } \beta \text { blockers or ACE inhibitors }{ }^{*}\end{array}$ & 135 (41) & $150(45)$ & $9(10)$ & $16(15)$ & $202(42)$ & $252(48)$ & $73(20)$ & $89(20)$ \\
\hline \multicolumn{9}{|l|}{ Combination treatment $\dagger$} \\
\hline No drug & $19(6)$ & $8(2)$ & $14(15)$ & $9(8)$ & $85(18)$ & $55(10)$ & $94(25)$ & $60(14)$ \\
\hline Any 1 category & $80(24)$ & $39(12)$ & $21(23)$ & $12(11)$ & $140(29)$ & $88(17)$ & $147(39)$ & $105(24)$ \\
\hline Any 2 categories & $160(48)$ & $115(34)$ & $38(42)$ & $32(29)$ & $195(40)$ & $196(38)$ & $96(26)$ & $136(31)$ \\
\hline Any 3 categories & $73(22)$ & $174(52)$ & $18(20)$ & $56(51)$ & $65(13)$ & $182(35)$ & $37(10)$ & $138(31)$ \\
\hline
\end{tabular}

*Includes thiazides, diuretics with potassium, vasodilator drugs, centrally acting antihypertensive drugs, adrenergic neurone blocking drugs, $\alpha$ blockers, angiotensin II antagonists, ganglion blocking drugs, tyrosine hydroxylase inhibitors, and calcium channel blockers.

†Antiplatelet drugs, statins, blood pressure lowering drug (angiotensin converting enzyme (ACE) inhibitor, $\beta$ blocker), and blood pressure lowering drugs other than $\beta$ blockers or ACE inhibitors.

drugs and statins were very widely used (particularly in patients with myocardial infarction). These data from representative samples of older men and women in primary care settings should be widely representative. By limiting analyses to subjects with confirmed general practitioner diagnoses, the study should avoid biases arising from using self reported diagnoses of coronary heart disease. Self reported use of medication was probably a more valid indication of medication usage but may not equate to medications prescribed. The methods used at both time points were identical, and the observed increase in secondary prevention over this time period is therefore likely to reflect a real change in clinical practice. Although subjects had aged by three to four years between the surveys, this is unlikely to explain the change, because older subjects are less likely to receive secondary prevention medication. ${ }^{3}$ Further potential exists for reducing the risk of recurrent coronary heart disease in older patients, particularly by improving the uptake of medication among patients with angina, and by more extensive use

\section{What is already known on this topic}

Combinations of treatment for secondary prevention of coronary heart disease (antiplatelet medication, statins, and antihypertensive drugs) reduce the risk of coronary heart disease substantially, but the extent of their use is not known

\section{What this study adds}

Uptake of secondary prevention increased markedly between 1998-2001 and 2003; by 2003 half of patients with myocardial infarction were using a combination of antiplatelet medication, statins, and blood pressure lowering drugs

Despite this, considerable opportunities remain for improving completeness of secondary prevention, especially in patients with angina of blood pressure lowering treatment, $\beta$ blockers, and ACE inhibitors.

Contributors: SER, PHW, and RWM developed the original idea for the paper, and SER wrote the first draft. SER, OP, and DAL performed the analyses. PHW, RWM, MCT, LTL, and SE contributed to the design and execution of the British Regional Heart Study, and DAL and SE to the design and execution of the British women's heart and health study. All authors contributed to interpretation of data and the final version of the manuscript, and all are guarantors.

Funding: The British regional heart study and the British women's heart and health study are funded by the Department of Health, England. The British Regional Heart Study is also a British Heart Foundation Research Group. DAL is funded by a career scientist award from the UK Department of Health. Competing interests: None declared.

Ethical approval: The British regional heart study and the British women's heart and health study have local (from each of the districts in which the study was based) and multicentre ethical committee approvals.

1 Department of Health. National service framework for coronary heart disease. London: DoH, 2000.

2 Wald NJ, Law MR. A strategy to reduce cardiovascular disease by more than $80 \%$. BMJ 2003;326:1419.

3 Lawlor DA, Whincup PH, Emberson JR, Rees K, Walker M, Ebrahim S. The challenge of secondary prevention for coronary heart disease in older patients: findings from the British women's heart and health study and the British regional heart study. Fam Pract 2004;21:582-6.

4 Walker M, Whincup PH, Shaper AG. The British regional heart study 1975-2004. Int J Epidemiol 2004;33:1185-92.

(Accepted 14 November 2005)

doi $10.1136 /$ bmj.38704.770127.BE

\section{Endpiece}

\section{Bonds of the profession}

Among the bonds that unite members of our profession, none are stronger than those that cause us to soar above all sectarian discord. We know no differences of race, creed or colour-every man is our neighbour.

Attributed to Sir Dominic Corrigan Brendan Judge, Penzance TR18 3LG 